\title{
What doctors need to know: prescribing or not for the oldest old.
}

\author{
KYDD, A. and FLEMING, A.
}

2016 


\section{What Doctors Need to Know : A narrative literature review on prescribing or not for the oldest old}

\section{Abstract}

Given the global increase in people over the age of 85 , there is a growing body of work concerning the oldest old. Much of this work is confined to the literature specialising in geriatrics and the more generic health care papers refer to 'older people' with little definition of what is meant by 'old'. latrogenesis (ill health caused by doctors) is a major issue and general practitioners (GPs) need practical help in prescribing for the oldest old. This paper presents a narrative review of the literature on prescribing and the oldest old. The results showed that all papers sourced referred to prescribing for the 'old' as those aged over 65, with only scant mention of oldest old. Yet prescribing for the oldest old involves clinical judgement and knowledge of the patient. It includes weighing up what will do good, cause no harm and is acceptable to the individual. GPs have to make treatment choices mostly in isolation from colleagues, during time-limited consultations and with few relevant guidelines on managing multi morbidities in the oldest old. A major issue in prescribing for people over the age of 85 is that guidelines for diseases are based on trials with younger adults, outline the best practice for one disease in isolation of other diseases and take little account of the interaction of drugs used in managing several diseases in frail older people. There is a growing body of work however calling for specialist services for the oldest old.

\section{Introduction}

The argument that age is a number and not a diagnosis is uncontested, but what appears to be missing from such arguments is that humans have a finite lifespan and as they age they become increasingly more susceptible to disease and have a decreasing amount of functional reserve to counteract physiological threats. An example of such differences can be seen in Scottish statistics, that show of the over $65 \mathrm{~s}, 65 \%$ of the population will have more than one chronic disease - but over the age of $85,82 \%$ of the population will have more than one chronic disease [1]. In looking at functional ability, people between 65 and 75 report limitations in activities of daily living similar to the $45-64$ year olds, but $25 \%$ of people over 85 reported moderate to severe functional limitations [2]. Getting the balance of when to prescribe, de-prescribe and not prescribe takes expertise, knowledge of the patient, compassion and courage. 
In treating any patient, doctors abide by the Hippocratic Oath. The most widely used version today appears to be that of Lasagna [3] which includes the following affirmations, which seem especially applicable to the care of the oldest-old:

'I will apply, for the benefit of the sick, all measures [that] are required, avoiding those twin traps of overtreatment and therapeutic nihilism...I will remember that there is art to medicine as well as science, and that warmth, sympathy, and understanding may outweigh the surgeon's knife or the chemist's drug...I will remember that I do not treat a fever...but a sick human being,whose illness may affect the person's family and economic stability. My responsibility includes these related problems, if I am to care adequately for the sick.'

It is clear from current literature, that doctors all take these affirmations seriously and question the 'twin traps' with regard to the prescribing treatment of the oldest-old and those with multiple comorbidities [4, 5, 6]. Guidelines on prescribing cannot replace clinical judgement, which involve improving quality of life for the individual and with the involvement of family/carers [6]. This involves patient-centred care, where shared decision-making, informed consent and continued monitoring are key. In ethical practice this means working in the patients' best interests and doing least harm.

The original aim of the paper was to explore issues concerning iatrogenesis in the oldest old, however it became apparent that issues concerning prescribing were central to this topic and thus the revised aim of the paper was to explore the positive and negative influences on prescribing practices. The findings of the narrative literature review are presented below.

\section{Methods for Reviewing the Literature}

The Preferred Reporting Items for Systematic Reviews and Meta-Analyses

(PRISMA) statement and flowchart was used to assist the authors in reporting on the existing literature regarding the topic area. 


\subsection{Data sources}

The following electronic databases were searched for full text, English language and peer-reviewed articles from January 2006 to January 2016: Medline, Pubmed CINAHL, Cochrane Library, ASSIA, Psychinfo, Google Scholar, Google. The keywords used were Frail elderly, iatrogenic disease, GP assessment, primary care.

\subsection{Criteria for inclusion/exclusion in the search strategy}

Articles were excluded where they referred solely to inpatients/hospitalised patients, were foreign language materials or no full text article was available. Both authors agreed to retain the remaining articles where there were clear implications for prescribing practices.

\subsection{Risk of bias assessment}

No disagreements required to be resolved regarding the inclusion/exclusion of the reviewed articles by the two authors.

\subsection{Findings}

The search strategy sourced 94 records. Following screening of all abstracts the decision was taken to retain only those from 2010 onwards $(n=72)$ to address relevance and currency. The 72 articles were reviewed, with a further 23 rejected. Following this screening, it was agreed to retain 49 articles (see Figure 1) INSERT FIGURE 1

\subsection{Abbreviations}


To avoid confusion the frequent terminologies used concerning prescribing (and mostly written as acronyms) are summarised in Table 1

INSERT TABLE 1

\section{Results}

The 49 papers selected for review from the search strategy were sorted into four themes (see Table 2). These were Potentially Inappropriate Medications (12), Geriatric Assessment (9), Clinical Decision Making (13), General Practitioner (GP) Training (15). The papers had overlap, but the main issues discussed determined the theme and they have been presented below.

\section{INSERT TABLE 2}

\subsection{Polypharmacy}

With advancing age comes not only an increasing incidence of disease, but an increasing use of medications which in turn leads to the risk of adverse drug events (ADEs) $[7,8,9,10,11]$. Polypharmacy is a major clinical issue and is rarely addressed by clinical guidelines which focus on single disease management [12, 13]. However best practice guidelines usually refer to the management of one disease, when older people have more than one presenting disease [13, 14]. For example, cardiovascular conditions account for the highest level of prescribing, which is consistent with good practice advocating the treatment with multiple medicines [12]. The majority of studies found that all drug related hospital admissions are caused by a small number of frequently used drugs. These are anticoagulants, Non-Steroidal Anti Inflammatory Drugs (NSAIDs), opioids and blood glucose lowering drugs $[15,16]$.Yet, multiple medications may improve quality of life and polypharmacy should not be synonymous with poor care $[12,17]$. 
Prescribing for older people is complex due to comorbidities, physical deterioration and age related changes in pharmacokinetics and pharmacodynamics and genetic conditions $(18,19,20]$. In a recent study, $20.8 \%$ of people with two clinical conditions were receiving 4-9 medications and $1.1 \%$ were receiving 10 or more medications - this rose to $47.7 \%$ (4-9 medications) and $41.7 \%$ ( 10 or over) in those with six or more clinical conditions [9]. Excessive medications contribute to poor adherence and a lower quality of life [12]. Inappropriate prescribing in the older populations worldwide is estimated to be between 10-40\% [21] and is an important and preventable cause of morbidity and mortality in older people [22]. Studies have shown that the risk of an ADE is $13 \%$ with the use of two medications, $58 \%$ with five medications and $82 \%$ with seven or more medications [23]. Of patients aged 60-69, $28.6 \%$ were on $4-9$ medications with $7.4 \%$ receiving 10 or more medications - this almost doubled for those aged 80 plus for $4-9$ medications (51.8\%) and more than doubled for those taking 10 or more medications (18.1\%) [9]. This means that older people are more susceptible to potentially inappropriate prescribing (PIP) and adverse drug reactions. Polypharmacy is associated with PIP, but factors not often acknowledged that also show a positive correlation with PIP, were the presence of depression, poor economic status, reduced cognition, a high comorbidity score and low functional status $[7,24]$.

\subsubsection{Potentially Inappropriate Prescribing (PIP)}

PIP covers over prescribing, underprescribing and mis-prescribing and is one of the main causes of ADEs. The focus of this issue has moved from detecting PIPs in hospital and long stay settings to primary care, because detection at this point this could be of greater benefit [7]. A recent UK study found a $16 \%$ increase in the rise of 
prescribing errors for each drug prescribed and a Taiwanese study found a $14 \%$ increase in lack of drug adherence for every medication prescribed [9]. A systematic literature review found the estimated prevalence of PIP across 23 European countries was $22.6 \%$ (30.9\% in Scotland on a sample size of 65,742 with a mean age of 75.2 years and $29 \%$ in the UK on a sample size of $1,019,491$ with a mean age of 75 years) using literature reporting on results from the Beers, STOPP and START criteria [7]. An independent study in Northern Ireland [23] found prevalence of 34\% on a sample size of 166,108 aged over 75 years. One US study [25] and one Australian study [18] found that frequent primary care visits to the frail elderly resulted in a lower risk of hospital admission. However this could be due to the individuals declining health, leaving them more at risk of PIPs or a sign that the person is receiving careful monitoring from the GP [18]. From the studies that explored the relationship between PIP and advanced age, approximately only half found a positive correlation [7]. So although polypharmacy is a risk for the oldest old, it is patients in their 60s and 70s that have the greatest number of medications [9].

\subsubsection{Potentially Inappropriate Medications (PIMs)}

PIMs have 3 categories, PIM-S (some Indications), PIM-R (rarely appropriate) and PIM-A (to be avoided) [26]. These distinctions are important as in a recent study, researchers found that patients over the age of 85 had a $53 \%$ chance of receiving PIMs and those aged $75-84$ a $25 \%$ chance of receiving PIMs over the $65-74$ year olds, yet the oldest group had a $28 \%$ lower odds of being prescribed a PIM-A [26]. One successful way of addressing PIMs has been shown in studies which employed pharmacist led medication reviews $[15,19,27,28]$. One Swedish study looked at life expectancy with and without polypharmacy and found that at 65 , approximately 8 of the remaining 20 years of life would be lived with polypharmacy. This increased to 
more than half of the remaining years when reaching 75 years. It also suggested that polypharmacy may be underestimated as the use of over-the-counter drugs may not be identified. The recommendations were that efforts should be made to reduce the number of years older people spend with polypharmacy [29].

\subsection{GP Training}

Multimorbity (the presence of two or more conditions) affects $60 \%$ of patients in primary care Sinnott et al 2015), although the incidence of disease has risen disproportionately to the changing demographics, possibly because of the increase in diagnosing what constitutes a disease ([2], 2014). Clinicians need more help in the management of patients with complex conditions as the resulting polypharmacy may incur ADEs $[14,30]$. The barriers to reviewing medications involved uncertainty by GPs in the absence of satisfactory guidelines, expertise in geriatric medicine and time issues [30].

GPs with a greater proportion of older patients were less likely to prescribe PIMs and PIM-A drugs [26], possibly due to more experience in caring for the complex medication management of the old [2]. Yet exposure to the old does not lead to expertise, and healthcare professionals receive scant training in the care of the frail old [2, 31, 32]. Education in care of the frail elderly was seen to positively influence decision making on prescribing $[22,30]$.

Little attention has been paid to frailty and the Comprehensive Geriatric Assessment (CGA) is not part of a GPs work. However GPs with specialist training in geriatrics are more likely to screen frail older people with a view to a more thorough assessment if required $[33,34]$ and this can avoid a hospital admission, as this group are least likely to benefit from such an admission [2]. 
One Canadian paper outlined the need for GPs to develop geriatric skills in order to provide a blend of curative and palliative skills to the frail old [2]. An Italian study reported that $25 \%$ of GPs had adequate knowledge of prescribing for old people, with $17 \%$ having poor knowledge $(n=155)$. The researchers found older physicians had less knowledge in prescribing for the oldest old [32]. An American study found that $72 \%(n=89)$ of doctors felt that inadequate education was one of the factors contributing to inappropriate prescribing [22].

Education is not always the answer, GPs are time limited and experience rafts of information each day, they need practice related information (what is the patient's experience of taking this medication, how do other GPs prescribe, what is the preparation of the drug like $[35,36,37]$. Various papers have described help for GPs to reduce PIPs with a degree of success $[21,38]$ but GPs can feel isolated in the treatment of multimorbidities and look to maintain the status quo rather than reviewing medications [30].

Knowing the patient, their choices and lifestyles have to be considered as if a medication regime is too onerous, patient adherence will be low. GPs were found to be 'satisficing' defined as giving care they deemed appropriate but not always optimal for a particular patient [30]. Satisficing involved 'relaxing targets for disease control, negotiating compromise with the patient, or making best guesses about the most appropriate course of action to take' [30:5]. This patient centred approach can be extended usefully to seeing how people cope in their own homes [2]. However a Canadian study pointed out that the frail old have been disadvantaged by health care reforms in that GPs rarely do house calls and the frail homebound old (and those in nursing homes) are becoming less visible to GPs. In calling for help for Canada's frailest old, the authors [2:699] recommend more GP trainee experience 'Let's take 
our trainees [GPs] to the coal face where these seniors reside and teach them how to make housecalls and visit nursing homes, so that the next generation of family doctors can develop confidence in this increasingly important work.'

\subsection{Geriatric Assessment for the Oldest Old}

A study reviewing approaches to screen and prevent the occurrence of ADRs in the oldest old identified this at risk population. It concluded that some strategies had little success in developing a robust risk measurement but reported favourably on the GerontoNET ADR risk score [27] . However, this tool was developed with inpatients, requires testing in different settings and needs further identification of risk factors. Findings showed that the number of drugs, coupled with a history of ADR's, was the strongest predictor of ADRs, followed by heart failure, liver disease, the presence of 4 or more conditions, and renal failure. The usefulness of medication reviews has already been highlighted, but was more successful in preventing ADRs when pharmacists were part of the geriatric multidisciplinary team. Furthermore this study found that a geriatric multidisciplinary team, combined with the use of the Comprehensive Geriatric Assessment, showed a 35\% reduction in the risk of a serious ADR and a substantial reduction in unnecessary and inappropriate drug use, when compared with usual care. The authors conclude that there is no single approach to preventing ADRs: safe drug use requires global assessment of the patients' clinical and functional strengths and weaknesses and the integration of multidisciplinary skills and knowledge in addressing the medical complexity of the older adult. One study addressed the most common conditions and medicines in the oldest old $(85+)$ in a primary care setting, arising from a recognition that there was a lack of data concerning the clinical characteristics of this group from which to 
develop patient-centred and evidenced based care [39]. The results showed that patients experienced 6.4 chronic conditions, and four of the most common of these were hypertension, dyslipidemia, atrial fibrillation and type 2 diabetes. Osteoporosis, hypothyroidism and gastro-esophageal reflux disease being more common in women and coronary artery disease more common in men. Prevalence of hypertension, osteoarthritis and osteoporosis increased with age, while dyslipidemia, diabetes and coronary artery disease decreased with age. Patients in this study were taking an average of 6.8 medications; but only three of the ten most common medications overall were for symptom relief, the remaining seven being for risk factor modification. The study concluded that this population must not be viewed as a heterogeneous group, and that the clinician must use a person centred approach in assessing the necessity of risk-modifying medications and the prioritisation of quality versus quantity of life. These findings were supported in an earlier study [40].

In a similar study of the oldest-old (85+) [41] the authors aimed to estimate trends in diagnosed disease and geriatric syndromes, polypharmacy and hospital admissions using the Clinical Practice Research Datalink. They found similar trends to the above studies $[39,40]$. One difference was an increase in the diagnosis of chronic kidney disease (CKD), based on abnormal laboratory results. This has been argued as an example of over diagnosis where 'normal' is poorly defined in the oldest old. In the instance of CKD in this study, the introduction of the Quality Outcomes Framework CKD register was thought to have influenced this increasing trend in diagnosis, even though the the standard did not account for advanced age. The authors also found increased trends in the diagnosis of osteoarthritis, osteoporosis and anaemia and conclude that these trends produce an 
urgency to question the appropriateness of multiple diagnostic labelling and the limited evidence of risks and benefits of multiple disease-specific interventions; and, that more debate is required surrounding the balance between a medical diagnosis led approach and geriatric approaches which aim to maintain or improve daily functioning and quality of life and which respect the patient's wishes.

Several authors have focused on the need for specialist services for the frail elderly

[34, 42], screening for frailty is time consuming which has led to a call for specialist clinics [43]. Such clinics could assess frailty at an earlier and reversible stage of disability and provide support to GPs in promoting the quality of life of older people. In contrast to providing new services, some authors propose the development of a tool to support decision-making on patients with multimorbidity in primary care settings [44]. This was based on the work of Stott and Davis, whose framework for GPs managing patients with multi morbidities, involved four elements: the management of the presenting problem(s); the management of continuing problems; modification of help-seeking behaviours; and, opportunistic health promotion. It is recognised that patients with multimorbidity may experience a cumulative burden of treatment and a minimally disruptive medicine approach is required [45]. This has led to the development of the Ariadne principles which are designed to assist doctors with both primary care consultations and patient contacts with other health professionals. Key to the process is putting the patient at the centre of care so that treatment goals are both shared with and prioritised by the patient. In recognition of the fact it is not always possible, or desirable, to address all of a patient's concerns in one consultation, the Ariadne principles are described as a comprehensive, longitudinal approach to the goal-oriented management of patients with 
multimorbidity in primary care. Like many other authors [14, 35], this paper recommends a critical approach to guidelines for this population, and that close attention needs to be paid to drug-drug, drug-disease and disease-disease interactions [44]

\subsection{Clinical Decision making}

One study presents a review of evidence based strategies to improve information for clinical decision-making; which includes optimising adherence, optimising geriatric prescribing, value of information and communication technologies to name but a few Topinkova et al (2012). As outlined in the Ariadne principles, knowledge of a patient's circumstances and quality of life issues is important in decision making. The person needs to know what is expected of them [14] and the GP can assess - in knowing the type of drug preparation whether or not this will help the patient with adherence [35]. Several papers refer to this as 'rational pharmacotherapy' [14. 35]. Studies have pointed to the argument that Evidence Based Medicine is a form of standardisation that contrasts with the individuality of patient care that lies in clinical judgement and a unique understanding of the individual that may seem irrational to an outsider [35]. Reeve and Bancroft [46] report on studies which query whether polypharmacy may link to an overly specialist model of care, and continue to state that overprescribing and the burden of polypharmacy is an iatrogenic phenomenon created by the existing systems and processes used for making decisions about medicines. They suggest that generalist care may be a means of reducing the burden of polypharmacy and tackling the problem of overprescribing. Generalist care is person, not disease oriented, taking a continuous rather than an episodic view of health experience, integrating biotechnical and biographical accounts in order to 
understand and address health as a resource for living and not an end in itself. Their Complex Needs service development project, involved additional GP home visits to carry out a generalist assessment and was designed around action learning principles. They found that GPs could see the nature and number of problems faced by the individual and could support improved delivery of care, including medicine and chronic disease management. This resulted in altered decisions about interventions including a reduction in prescribing and associated surveillance. Such an approach has been advocated by many [47].

Geriatric pharmacotherapy is a complex process, involving age appropriate drug development and manufacturing, appropriate drug testing in clinical trials, rational and safe prescribing, reliable administration and assessment of drug effects, including adherence measurement and age appropriate outcomes measurement This complexity leads to numerous opportunities for errors to occur [20]. The first major breakthrough in providing guidance for doctors was by Dr Mark Beers in 1991, which was revised in 2003 [10] and 2013 [48] and in 2015 [49]. Beers provided a set of criteria for PIP, which have been used successfully by practitioners prescribing for older people [10, 18]. However, the Beers criteria is not without its critics; examples include - it includes drugs not available in Europe, it does not include drug-drug interactions (DDIs), does not consider prescribing omissions and is dated [10, 26, 49]. A new set of criteria was devised in 2003 , known as STOPP (Screening Tool of Older Person's Prescriptions) and START (Screening Tool to Alert to Right Treatment) [50]. Again, these criteria are criticised as they relied on review articles and not clinical trials and are in need of updating [10]. However, one study comparing the Beers and STOPP found that the STOPP was a more sensitive measure of PIP and of great benefit in primary care settings [16]. In contrast some 
researchers found the Beers criteria to be more sensitive than the STOPP criteria; however they concluded that both criteria were suitable as medication review care tools to improve care for the elderly [51]. An Irish study used a subset of the STOPPISTART criteria to explore the prevalence of PIP and PPO in a population based sample of people aged $65+$. Unsurprisingly they found polypharmacy to be associated with both PIP and PPO, however they also found PPO to be twice as prevalent as PIP [52] . A further set, the Medication Appropriateness Index (MAI) criteria was developed by an expert group in Italy in 2007 and updated in 2011 [21, 26]. This is described as a judgement-based process measure. This tool assesses ten elements of prescribing, resulting in a weighted score that summarises prescribing appropriateness. The limitations of this tool are that it is time-consuming, and does not assess under-prescribing [27] .

A systematic overview identified 46 tools to assess inappropriate prescribing in 2014 [53]. They could be grouped into implicit (clinical judgement), explicit (criterion based) and a mixture of both. However, the tools are useful in alerting prescribers to inappropriate prescribing and no tool will ever substitute for clinical judgement [10, 53].

\section{Discussion}

Polypharmacy is increasing, driven by an increase in the numbers of older people, an increase in diagnostics and accompanying age-related multiple chronic conditions, with an increase in treatment guidelines designed to address a single conditions [9].

We suggest that in order to add to the debate, definitions need to be agreed amongst researchers, clinicians and educators. For example, all papers reviewed 
addressed the old, classing this group as 65 plus. Yet there is growing evidence that the needs of the frail old - or oldest old - those aged 85 plus are a marginalised and highly vulnerable group in need of different and distinctive services [2] which sets them apart from their younger 'old' counterparts. Evidence supports the need for frailty focused services, multidisciplinary input - to include a pharmacist and for information sharing amongst GPs [31].

In turn polypharmacy and comorbidity/multimorbidity also need to be more clearly defined: It is been reported that there are conflicting definitions of these terms [39]. In our review we found comorbidity defined as two [30], three [41] or multiple co-existing conditions [1] and polypharmacy defined as five [17, 29, 34] or several medications $[13,14]$, or over 10 , referring to excessive polypharmacy over varying periods of time [24] .

In addition, the assumption that polypharmacy is dangerous should be balanced against clinical judgement and careful assessment by the prescriber [12], thus placing on value on clinical judgement and rational pharmacotherapy. Polypharmacy is often viewed as a synonym for poor care and perhaps suboptimal prescribing best describes poor care associated with inappropriate prescribing [12]. Few older patients with polypharmacy are included in pharmacological trials $[20,27]$, and therefore the safety profile of many drugs in this population is still debated [41]. Drug-disease interaction in relation to comorbidity is discussed, giving one example of some beta-blockers (taken for heart disease or high blood pressure) worsening asthma and masking hypoglycaemia in diabetic patients. It is also stated that guidelines need to take into account conditions which may alter drug metabolism, such as kidney and liver diseases, that lead to a reduced drug clearance and therefore to a higher risk of ADRs. The presence of cognitive or 
functional deficits may cause a reduced ability to comply with medication instructions as well as a potentially reduced ability to report any ADRs [41].

What appear to be needed are guidelines for the management of more than one condition. Citing a recent systematic review of patterns of multimorbidity, one paper stated that the most common pair of conditions was osteoarthritis and a cardiometabolic condition such as hypertension, diabetes, obesity or ischaemic heart disease [1].

Thus, in placing groups of conditions together, multiple methods of treatment can be discussed. This has also been trialled on computer-based prescribing systems which aim to help doctors reduce prescribing errors, improve prescribing appropriateness and lead to a reduction in iatrogenic illness. To date these systems have had mixed outcomes: showing strong potential for changing prescriber behaviours but limited success in demonstrating improved patient outcomes [27] . The overall quality of life for the oldest old is a priority for clinical and interventional health care research [19]. What is deemed appropriate and inappropriate prescribing may only be determined by the individual patient [14].

In summary, multimorbidity and polypharmacy need to be viewed in tandem - they are two sides of the same coin [14]. Publications have started to appear to address such issues such as Guthrie et al in 2012 [54]; a Kings Fund publication in 2013 [55] and NICE guidelines on medicine optimisation in 2015 [56].

\section{References}

[1] Wallace, E., Salisbury, C., Guthrie, B., Lewis, C., Fahey, T., \& Smith, S. M. (2015). Managing patients with multimorbidity in primary care. BMJ, 350, h176. doi:doi: 10.1136/bmj.h176

[2] McGregor, M. J., \& Sloan, J. (2014). Realigning training with need: A case for mandatory family medicine resident experience in community-based care of the frail 
elderly. Can Fam Physician, 60(8), 697-699, 704-697. Retrieved from http://www.ncbi.nlm.nih.gov/pmc/articles/PMC4131952/pdf/0600697.pdf

[3] Lasagna, L. 1964 Hippocratic Oath: Modern Version Tufts University http://www.guides.library.jhu.edu/c.php?g=202502\&p=1335759

[4] Magin, P., Goode, S., \& Pond, D. (2015). GPs, medications and older people: A qualitative study of general practitioners' approaches to potentially inappropriate medications in older people. Australasian Journal on Ageing, 34(2), 134-139 136p. doi:10.1111/ajag.12150

[5] Marengoni, A., Nobili, A., \& Onder, G. (2015). Best Practices for Drug Prescribing in Older Adults: A Call for Action. Drugs Aging, 32(11), 887-890.

doi:10.1007/s40266-015-0324-3

[6] Wallis, K. A. (2015). Ageing is not for the faint-hearted: are we making it worse? Polypharmacy-related harm in the elderly. Journal Of Primary Health Care, 7(3), 167-169.

[7] Tommelein, E., Mehuys, E., Petrovic, M., Somers, A., Colin, P., \& Boussery, K. (2015). Potentially inappropriate prescribing in community-dwelling older people across Europe: a systematic literature review. Eur J Clin Pharmacol, 71(12), 14151427. Retrieved from http://download.springer.com/static/pdf/152/art\%253A10.1007\%252Fs00228-0151954-

4.pdf? originUrl=http $\% 3 \mathrm{~A} \% 2 \mathrm{~F} \% 2 \mathrm{Flink}$.springer.com $\% 2 \mathrm{Farticle} \% 2 \mathrm{~F} 10.1007 \% 2 \mathrm{Fs} 002$ 28-015-1954-

4\&token2=exp $=1457624069 \sim a c l=\% 2 F$ static $\% 2 F p d f \% 2 F 152 \% 2 F a r t \% 25253 \mathrm{~A} 10.100$ 7\%25252Fs00228-015-1954-

4.pdf\%3ForiginUrl\%3Dhttp $\% 253 \mathrm{~A} \% 252 \mathrm{~F} \% 252 \mathrm{Flink}$.springer.com $\% 252$ Farticle $\% 252$ F10.1007\%252Fs00228-015-1954-

$\underline{4^{*} \sim \mathrm{hmac}=41 \mathrm{fbd} 5460 \mathrm{~d} 7 \mathrm{~b} 5336 \mathrm{fc} 9513 \mathrm{e} 88 \mathrm{e} 12 \mathrm{e} 9 \mathrm{f} 31869 \mathrm{bbd} 82 \mathrm{f} 19 \mathrm{ad} 07964 \mathrm{~b} 4924 \mathrm{~d} 6 \mathrm{~d} 9 \mathrm{~d}}$ $\underline{\mathrm{e} 6 \mathrm{c}}$

[8] Sweeney, J., Laoire, F. O., Linehan, G., \& Herlihy, D. (2015). A Review of Potentially Inappropriate Prescribing in Over 65's in Livinghealth Clinic. Irish Medical Journal, 108(6), 180-181. Retrieved from

https://login.ezproxy.napier.ac.uk/login?url=http://search.ebscohost.com/login.aspx?

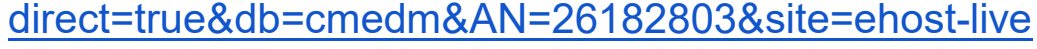

[9] Payne, R. A., Avery, A. J., Duerden, M., Saunders, C. L., Simpson, C. R., \& Abel, G. A. (2014). Prevalence of polypharmacy in a Scottish primary care population. Eur J Clin Pharmacol, 70(5), 575-581. doi:10.1007/s00228-013-1639-9

[10] Yayla, M. E., Bilge, U., Binen, E., \& Keskin, A. (2013). The use of

START/STOPP criteria for elderly patients in primary care. Thescientificworldjournal, 2013, 165873-165873. doi:10.1155/2013/165873 
[11] Cahir, C., Bennett, K., Teljeur, C., \& Fahey, T. (2014). Potentially inappropriate prescribing and adverse health outcomes in community dwelling older patients. British journal of clinical pharmacology, 77(1), 201-210. doi:10.1111/bcp.12161

[12] Payne, (2) R. A., Abel, G. A., Avery, A. J., Mercer, S. W., \& Roland, M. O. (2014). Is polypharmacy always hazardous? A retrospective cohort analysis using linked electronic health records from primary and secondary care. British journal of clinical pharmacology, 77(6), 1073-1082. doi:10.1111/bcp.12292

[13] Marengoni,(2) A., \& Onder, G. (2015). Guidelines, polypharmacy, and drug-drug interactions in patients with multimorbidity. BMJ, 350, h1059. Retrieved from http://www.bmj.com/content/bmj/350/bmj.h1059.full.pdf

[14] Sinnott, C., \& Bradley, C. P. (2015). Multimorbidity or polypharmacy: two sides of the same coin? Journal of Comorbidity, 5 (1), 29-31.

[15] Teichert, M., Luijben, S. N., Wereldsma, A., Schalk, T., Janssen, J., Wensing, M., \& de Smet, P. (2013). Implementation of medication reviews in community pharmacies and their effect on potentially inappropriate drug use in elderly patients. International Journal Of Clinical Pharmacy, 35(5), 719-726. doi:10.1007/s11096-0139794-8

[16] Cahir, C., Moriarty, F., Teljeur, C., Fahey, T., \& Bennett, K. (2013). Potentially inappropriate prescribing and vulnerability and hospitalization in older communitydwelling patients. The Annals Of Pharmacotherapy, 48(12), 1546-1554.

doi:10.1177/1060028014552821

[17] Raschi, E., Piccinni, C., Signoretta, V., Lionello, L., Bonezzi, S., Delfino, M., .. . Carati, D. (2015). Clinically important drug-drug interactions in poly-treated elderly outpatients: a campaign to improve appropriateness in general practice. British journal of clinical pharmacology, 80(6), 1411-1420. Retrieved from http://onlinelibrary.wiley.com/store/10.1111/bcp.12754/asset/bcp12754.pdf?v=1\&t=il mf0mub\&s=a0084033235e51fecf8e526d925e746931dc1eff

[18] Price, S. D., Holman, C. D., Sanfilippo, F. M., \& Emery, J. D. (2015). Does ongoing general practitioner care in elderly patients help reduce the risk of unplanned hospitalization related to Beers potentially inappropriate medications? Geriatrics \& Gerontology International, 15(8), 1031-1039 1039p.

doi:10.1111/ggi.12400

[19] Milos, V., Rekman, E., Bondesson, Å., Eriksson, T., Jakobsson, U., Westerlund, T., \& Midlöv, P. (2013). Improving the quality of pharmacotherapy in elderly primary care patients through medication reviews: a randomised controlled study. Drugs Aging, 30(4), 235-246. doi:10.1007/s40266-013-0057-0

[20] Topinkova, E., Baeyens, J. P., Michel, J. P., \& Lang, P. O. (2012). Evidencebased strategies for the optimization of pharmacotherapy in older people. Drugs Aging, 29(6), 477-494. doi:10.2165/11632400-000000000-00000 
[21] Lopatto, J., Keith, S. W., Del Canale, S., Templin, M., \& Maio, V. (2014).

Evaluating sustained quality improvements: long-term effectiveness of a physicianfocused intervention to reduce potentially inappropriate medication prescribing in an older population. Journal of clinical pharmacy and therapeutics, 39(3), 266-271. doi:10.1111/jcpt.12137

[22] Ramaswamy, R., Maio, V., Diamond, J. J., Talati, A. R., Hartmann, C. W., Arenson, C., \& Roehl, B. (2011). Potentially inappropriate prescribing in elderly: assessing doctor knowledge, confidence and barriers. Journal Of Evaluation In Clinical Practice, 17(6), 1153-1159. doi:10.1111/j.1365-2753.2010.01494.x

[23] Bradley, M. C., Fahey, T., Cahir, C., Bennett, K., O'Reilly, D., Parsons, C., \& Hughes, C. M. (2012). Potentially inappropriate prescribing and cost outcomes for older people: a cross-sectional study using the Northern Ireland Enhanced Prescribing Database. Eur J Clin Pharmacol, 68(10), 1425-1433. doi:10.1007/s00228-012-1249-y

[24] Moriarty, F., Hardy, C., Bennett, K., Smith, S. M., \& Fahey, T. (2015). Trends and interaction of polypharmacy and potentially inappropriate prescribing in primary care over 15 years in Ireland: a repeated cross-sectional study. BMJ open, 5(9), e008656. Retrieved from http://www.ncbi.nlm.nih.gov/pmc/articles/PMC4577876/pdf/bmjopen-2015008656.pdf

[25] Pugh, J. A., Wang, C.-P., Espinoza, S. E., Noël, P. H., Bollinger, M., Amuan, M., ... Pugh, M. J. (2014). Influence of frailty-related diagnoses, high-risk prescribing in elderly adults, and primary care use on readmissions in fewer than 30 days for veterans aged 65 and older. Journal of the American Geriatrics Society, 62(2), 291298. doi:10.1111/jgs.12656

[26] Amos, T. B., Keith, S. W., Del Canale, S., Orsi, P., Maggio, M., Baccarini, S., . . . Maio, V. (2015). Inappropriate prescribing in a large community-dwelling older population: a focus on prevalence and how it relates to patient and physician characteristics. Journal of clinical pharmacy and therapeutics, 40(1), 7-13. doi:10.1111/jcpt.12212

[27] Onder, G., van der Cammen, T. J. M., Petrovic, M., Somers, A., \& Rajkumar, C. (2013). Strategies to reduce the risk of iatrogenic illness in complex older adults. Age And Ageing, 42(3), 284-291. doi:10.1093/ageing/aft038

[28] Clyne, B., Smith, S. M., Hughes, C. M., Boland, F., Bradley, M. C., Cooper, J. A., . . . OPTI-SCRIPT study team. (2015). Effectiveness of a Multifaceted Intervention for Potentially Inappropriate Prescribing in Older Patients in Primary Care: A Cluster-Randomized Controlled Trial (OPTI-SCRIPT Study). Annals of Family Medicine, 13(6), 545-553 549p. doi:10.1370/afm.1838

[29] Wastesson, J. W., Canudas-Romo, V., Lindahl-Jacobsen, R., \& Johnell, K. (2016). Remaining Life Expectancy With and Without Polypharmacy: A RegisterBased Study of Swedes Aged 65 Years and Older. Journal of the American Medical Directors Association, 17(1), 31-35. Retrieved from http://ac.els- 
cdn.com/S1525861015004946/1-s2.0-S1525861015004946main.pdf? tid=cf49c1a2-e6d2-11e5-a082$\underline{00000 a a c b 35 d \& a c d n a t=1457623060 \quad 299210 d b e a 17260 b 226 e 3615 a 126 f 3 c a}$

[30] Sinnott, C., Mercer, S. W., Payne, R. A., Duerden, M., Bradley, C. P., \& Byrne, M. (2015). Improving medication management in multimorbidity: development of the MultimorbiditY COllaborative Medication Review And DEcision Making (MY COMRADE) intervention using the Behaviour Change Wheel. Implementation Science, 10(1), 132.

[31] Ryan, D., Barnett, R., Cott, C., Dalziel, W., Gutmanis, I., Jewell, D., . . Puxty, J. (2013). Geriatrics, interprofessional practice, and interorganizational collaboration: a knowledge-to-practice intervention for primary care teams. The Journal Of Continuing Education In The Health Professions, 33(3), 180-189.

doi:10.1002/chp.21183

[32] Maio, V., Jutkowitz, E., Herrera, K., Abouzaid, S., Negri, G., \& Del Canale, S. (2011). Appropriate medication prescribing in elderly patients: how knowledgeable are primary care physicians? A survey study in Parma, Italy. Journal of clinical pharmacy and therapeutics, 36(4), 468-480. Retrieved from http://onlinelibrary.wiley.com/store/10.1111/j.1365-2710.2010.01195.x/asset/j.13652710.2010.01195.x.pdf?v=1\&t=ilmebr2m\&s=d9ca18852be7d9702722ffec28745ef66 $\underline{7 \mathrm{cae} 81 \mathrm{f}}$

[33] Pialoux, T., Goyard, J., \& Lesourd, B. (2012). Screening tools for frailty in primary health care: a systematic review. Geriatrics \& Gerontology International, 12(2), 189-197. doi:10.1111/j.1447-0594.2011.00797.x

[34] Leendertse, A. J., de Koning, G. H. P., Goudswaard, A. N., Belitser, S. V., Verhoef, M., de Gier, H. J., . . van den Bemt, P. M. L. A. (2013). Preventing hospital admissions by reviewing medication (PHARM) in primary care: an open controlled study in an elderly population. Journal of clinical pharmacy and therapeutics, 38 (5), 379-387. doi:10.1111/jcpt.12069

[35] Wadmann, S., \& Bang, L. E. (2015). Rationalising prescribing: Evidence, marketing and practice-relevant knowledge. Social Science \& Medicine, 135, 109 116 108p. doi:10.1016/j.socscimed.2015.04.032

[36] Rognstad, S., Brekke, M., Fetveit, A., Dalen, I., \& Straand, J. (2013). Prescription peer academic detailing to reduce inappropriate prescribing for older patients: a cluster randomised controlled trial. The British Journal Of General Practice: The Journal Of The Royal College Of General Practitioners, 63(613), e554e562. doi:10.3399/bjgp13X670688

[37] Lenander, C., Bondesson, Å., Midlöv, P., \& Viberg, N. (2015). Healthcare system intervention for safer use of medicines in elderly patients in primary care--a qualitative study of the participants' perceptions of self-assessment, peer review, feedback and agreement for change. BMC family practice, 16(117).

doi:10.1186/s12875-015-0334-6 
[38] Keith, S. W., Maio, V., Dudash, K., Templin, M., \& Del Canale, S. (2013). A physician-focused intervention to reduce potentially inappropriate medication prescribing in older people: a 3-year, Italian, prospective, proof-of-concept study. Drugs Aging, 30(2), 119-127. doi:10.1007/s40266-012-0043-y

[39] Tsoi, C. S., Chow, J. Y., Choi, K. S., Li, H.-W., Nie, J. X., Tracy, C. S., . . Upshur, R. E. G. (2014). Medical characteristics of the oldest old: retrospective chart review of patients aged $85+$ in an academic primary care centre. BMC Research Notes, 7, 340-340. doi:10.1186/1756-0500-7-340

[40] Schuling, J., Gebben, H., Johannes Gerardus Veehof, L., \& Marcia HaaijerRuskamp, F. (2012). Deprescribing medication in very elderly patients with multimorbidity: the view of Dutch GPs. A qualitative study. BMC family practice, 13(1), 56-62 57p. doi:10.1186/1471-2296-13-56

[41] Melzer, D., Tavakoly, B., Winder, R. E., Masoli, J. A. H., Henley, W. E., Ble, A., \& Richards, S. H. (2015). Much more medicine for the oldest old: trends in UK electronic clinical records. Age And Ageing, 44(1), 46-53. doi:10.1093/ageing/afu113

[42] Hoogendijk, E. O., van der Horst, H. E., Deeg, D. J. H., Frijters, D. H. M., Prins, B. A. H., Jansen, A. P. D., . . van Hout, H. P. J. (2013). The identification of frail older adults in primary care: comparing the accuracy of five simple instruments. Age And Ageing, 42(2), 262-265. doi:10.1093/ageing/afs163

[43] Tavassoli, N., Guyonnet, S., Abellan Van Kan, G., Sourdet, S., Krams, T., Soto, M. E., . . Vellas, B. (2014). Description of 1,108 older patients referred by their physician to the "Geriatric Frailty Clinic (G.F.C) for Assessment of Frailty and Prevention of Disability" at the gerontopole. The Journal Of Nutrition, Health \& Aging, 18(5), 457-464. doi:10.1007/s12603-014-0462-z

[44] Muth, C., van den Akker, M., Blom, J. W., Mallen, C. D., Rochon, J., Schellevis, F. G., . . . Kirchner, H. (2014). The Ariadne principles: how to handle multimorbidity in primary care consultations. BMC medicine, 12(1), 223.

[45] Muth, C., Beyer, M., Fortin, M., Rochon, J., Oswald, F., Valderas, J. M., . . van den Akker, M. (2014). Multimorbidity's research challenges and priorities from a clinical perspective: The case of 'Mr Curran'. European Journal of General Practice, 20(2), 139-147 139p. doi:10.3109/13814788.2013.839651

[46] Reeve, J., \& Bancroft, R. (2014). Generalist solutions to overprescribing: a joint challenge for clinical and academic primary care. Primary Health Care Research \& Development, 15(1), 72-79. doi:10.1017/S1463423612000576

[47] Treadwell, J. (2015). Coping with complexity: working beyond the guidelines for patients with multimorbidities. Journal of Comorbidity, 5(1), 11-14.

[48] The American Geriatrics Society Beers Criteria Update Expert, P. (2012). American Geriatrics Society Updated Beers Criteria for Potentially Inappropriate Medication Use in Older Adults. Journal of the American Geriatrics Society, 60(4), 616-631. doi:10.1111/j.1532-5415.2012.03923.x 
[49] Steinman, M. A., Beizer, J. L., DuBeau, C. E., Laird, R. D., Lundebjerg, N. E., \& Mulhausen, P. (2015). How to use the American Geriatrics Society 2015 Beers Criteria-A guide for patients, clinicians, health systems, and payors. Journal of the American Geriatrics Society, 63(12), e1-e7. Retrieved from http://onlinelibrary.wiley.com/store/10.1111/jgs.13701/asset/jgs13701.pdf?v=1\&t=ilmf 0ta0\&s=600a9905641ed8177c238d01c2f46c9565e16b00

[50] O'Mahony, D., O'Sullivan, D., Byrne, S., O'Connor, M. N., Ryan, C., \& Gallagher, P. (2014). STOPP/START criteria for potentially inappropriate prescribing in older people: version 2. Age And Ageing, afu145.

[51] Oliveira, M. G., Amorim, W. W., Jesus, S. R., Heine, J. M., Coqueiro, H. L., \& Passos, L. C. S. (2015). A comparison of the Beers and STOPP criteria for identifying the use of potentially inappropriate medications among elderly patients in primary care. Journal Of Evaluation In Clinical Practice, 21(2), 320-325 326p. doi:10.1111/jep.12319

[52] Galvin, R., Moriarty, F., Cousins, G., Cahir, C., Motterlini, N., Bradley, M., . . . Kenny, R.-A. (2014). Prevalence of potentially inappropriate prescribing and prescribing omissions in older Irish adults: findings from The Irish LongituDinal Study on Ageing study (TILDA). Eur J Clin Pharmacol, 70(5), 599-606. doi:10.1007/s00228-014-1651-8

[53] Kaufmann, C. P., Tremp, R., Hersberger, K. E., \& Lampert, M. L. (2014). Inappropriate prescribing: a systematic overview of published assessment tools. Eur J Clin Pharmacol, 70(1), 1-11. doi:10.1007/s00228-013-1575-8

[54] Guthrie, B, Payne, K., Alderson, P, McMurdo, M., Mercer, S. (2012) Adapting clinical guidelines to take account of multimorbidity. BMJ. 345: e6341

[55] Duerden, M., Avery, A.. Payne, R. (2013) Polypharmacy and medicines optimisation: Making it safe and sound. Kings Fund, London

[56] NICE Guideline (2015) Medicines optimisation: the safe and effective use of medicines to enable the best possible outcomes. Available at http://www.nice.org.uk/guidance/ng5. Accessed February 2016 
Figure 1. Flow diagram of article selection

\section{Search Criteria}

Key Words: Frail elderly, iatrogenic disease, GP assessment, primary care

Databases: Medline, Pubmed CINAHL, Cochrane Library, ASSIA, Psychinfo, Google Scholar, Google

Exclusions: Inpatients/hospitalised; Non-english language

Dates: Jan. 2006 - Jan. 2016

\section{Results}

94 records: 22 pre-2010 and 72 from 2010 onwards. Decision taken to retain only those from 2010 onwards to ensure currency of the literature.

\begin{tabular}{|l|}
\hline \multicolumn{1}{|c|}{ First Screening $(\mathbf{N}=\mathbf{7 2})$} \\
Rejected as no full text available $=15$ \\
Rejected as no results available $=3$ \\
Rejected as results inconclusive $=5$ \\
Retained: 49
\end{tabular}


Table 1: List of Abbreviations

\begin{tabular}{|c|c|}
\hline List of Abbreviations: & Definition \\
\hline $\begin{array}{l}\text { PIP - Potentially inappropriate } \\
\text { prescribing }\end{array}$ & $\begin{array}{l}\text { 'The prescribing of medication that could introduce significant } \\
\text { risk of an ADE in particular when there is an equally or more } \\
\text { effective alternative with a lower risk available' (Tommelein et } \\
\text { al, 2015:1416;). } \\
\text { - over prescribing, The prescription of an unnecessary } \\
\text { medication } \\
\text {-underprescribing The omission of a medication that is } \\
\text { necessary } \\
\text {-mis-prescribing. The incorrect prescription of an indicated } \\
\text { medication (covering drug choice, doseage, duration of } \\
\text { therapy; duplication and drug-drug and drug-food interactions } \\
\text { (Kauffman et al, 2014) }\end{array}$ \\
\hline $\begin{array}{l}\text { PIM - Potentially inappropriate } \\
\text { medication: } \\
\text { - there are three categories, } \\
\text { PIM-A ; PIM- R; and PIM- } \\
\text { S (Amos et al,2015) }\end{array}$ & $\begin{array}{l}\text { Medications with risks that outweigh the potential benefits for } \\
\text { older adults: } \\
\text { PIM - A - Potentially inappropriate medication - avoid } \\
\text { PIM - R - Potentially inappropriate medication - rarely } \\
\text { appropriate } \\
\text { PIM-S- Potentially inappropriate medication - some indications }\end{array}$ \\
\hline ADE - Adverse drug effects & $\begin{array}{l}\text { An event which results in unintended harm to the patient and is } \\
\text { related to the care and/or services provided to the patient, } \\
\text { rather than to the patient's underlying medical conditions } \\
\text { (Cahir et al, 2013) }\end{array}$ \\
\hline ADR - Adverse drug reactions & $\begin{array}{l}\text { Type A -an exaggerated response to the expected action of } \\
\text { the drug (Onder et al, 2013) } \\
\text { Type B - a novel response to a drug that are not expected } \\
\text { from the known pharmacological actions of the drug. } \\
\text { Type C - 'continuing' reactions, persist for a relatively long } \\
\text { time. } \\
\text { Type D - 'delayed' reactions, become apparent some time } \\
\text { after the use of a medicine. } \\
\text { Type E - 'end-of-use' reactions, are associated with the } \\
\text { withdrawal of a medicine. } \\
\text { (Medicines and Healthcare Products Regulatory Agency) }\end{array}$ \\
\hline $\begin{array}{l}\text { PPO - Potential prescribing } \\
\text { omissions }\end{array}$ & $\begin{array}{l}\text { The omission of clinically indicated medications (Ryan et al } \\
\text { 2012) }\end{array}$ \\
\hline DDI - Drug-drug interactions & $\begin{array}{l}\text { When the effects of one drug are modified by the concomitant } \\
\text { or subsequent use of another. }\end{array}$ \\
\hline IM - Inappropriate medications & $\begin{array}{l}\text { Medications that pose potential risks outweighing potential } \\
\text { benefits. }\end{array}$ \\
\hline DRPs - Drug related problems & $\begin{array}{l}\text { A DRP exists when a patient experiences or is likely to } \\
\text { experience either a disease or symptom having an actual or } \\
\text { suspected relationship with drug therapy. }\end{array}$ \\
\hline $\begin{array}{l}\text { DTPs - Drug therapy-related } \\
\text { problems }\end{array}$ & $\begin{array}{l}\text { A DTP exists when a patient experiences or is likely to } \\
\text { experience either a disease or symptom having an actual or } \\
\text { suspected relationship with drug therapy. }\end{array}$ \\
\hline
\end{tabular}


Table 2. Thematic Analysis of the Abstracts of the Articles Reviewed.

\begin{tabular}{|c|l|}
\hline Theme & \multicolumn{1}{|c|}{ Number of Articles } \\
\hline Polypharmacy & 12 \\
\hline Geriatric Assessment & 9 \\
\hline Clinical Decision Making & 13 \\
\hline General Practitioner Training & 15 \\
\hline \hline Four Themes & Total: 49 \\
\hline
\end{tabular}

